\title{
PENGEMBANGAN MEDIA PEMBELAJARAN POHON PINTAR PADA MATERI PENJUMLAHAN PADA KELAS I SDN 52 PARUPUK TABING (STUDI BERDASARKAN ASESMEN)
}

\author{
Syafni Gustina Sari ${ }^{1}$, Ambiyar $^{2}$, Ishak Aziz ${ }^{3}$ Citra Leffega $^{4}$ \\ 1,2,3 Program Doktor Ilmu Pendidikan Pasca Sarjana, Universitas Negeri Padang \\ ${ }^{4}$ Pendidikan Guru Sekolah Dasar, Universitas Bung Hatta \\ syafnigustinasari@yahoo.co.id
}

\begin{abstract}
This research is motivated by the lack of availability of media available in schools on sum material. This study This study aims to produce a smart tree learning media on the material of the summation in grade I of 52 Parupuk Tabing that meets valid and practical criteria. This type of research is development research, the development model used is the 4-D development model, namely defining, designing, developing, and disseminating it, but in this research it is up to the development stage due to time constraints. This research was conducted in the even semester of the 2019/2020 school year with the material of summation. The research instrument included a validation sheet and a practicality sheet (teacher and student response questionnaires). In the validation process, the media is validated by one material expert and one media expert. In the practicality process, the media was tried out on 21 students. Based on the research, the development of Smart Tree learning media on the summation material in grade I SD on material validation fulfills very valid criteria with the proportion of results of $91 \%$, and meets valid criteria with a proportion of $85.5 \%$ in media validation. The Smart Tree Media that has been developed is categorized as practical by the teacher with an average proportion of $86.6 \%$ and is categorized as very practical by students with a proportion of $95.4 \%$. So it can be concluded that the smaet tree learning media on the material for summation of the material for summation of the sub-themas like to exercise in the first grade of elementary school is valid and pratical so that it can be used as a learning medium
\end{abstract}

Keywords: Development, Mathematics Learning Media, Smart Tree.

\begin{abstract}
Abstrak
Penelitian ini dilatarbelakangi oleh kurangnya ketersediaan media yang ada di sekolah pada materi penjumalahan. Penelitian ini bertujuan untuk menghasilkan media pembelajaran Pohon pintar pada Materi Penjumlahan Pada Kelas I SDN 52 Parupuk Tabing memenuhi kriteria valid dan praktis. Jenis penelitin ini adalah penelitian pengembangan, model penelitian pengembangan yang digunakan adalah model pengembangan 4-D yaitu define, design, develop, dan disseminate tetapi pada penelitian ini hanya sampai tahap develop (pengembangan) dikarenakan keterbatasan waktu. Penelitian ini dilakukan pada semester genap tahun ajaran 2019/2020 dengan materi penjumlahan. Instrumen penelitian meliputi lembar validasi dan lembar praktikalitas (angket respon guru dan siswa). Pada proses validasi, media divalidasi oleh satu orang ahli materi dan satu orang ahli media. Pada proses praktikalitas, media diujicobakan kepada 21 orang siswa. Berdasarkan hasil penelitian, pengembangan media pembelajaran Pohon Pintar pada materi penjumlahan pada kelas I SD pada validasi materi memenuhi kriteria sangat valid dengan persentase penilaian sebesar 91\%, dan memenuhi kriteria valid dengan persentase $85,5 \%$ pada validasi media. Media Pohon Pintar yang telah dikembangkan dikategorikan praktis oleh guru dengan rata-rata persentase $86,6 \%$ dan dikategorikan sangat praktis oleh peserta didik dengan persentase 95,4\%. Jadi, dapat disimpulkan bahwa media pembelajaran Pohon Pintar pada materi penjumlahan pada kelas I SD valid dan praktis sehingga dapat digunakan sebagai salah satu media pembelajaran.
\end{abstract}

Kata Kunci: Pengembangan, Media Pembelajaran Matematika, Pohon Pintar

\section{PENDAHULUAN}

Di Sekolah Dasar, banyak mata pelajaran yang dipelajari untuk memperleh pengetahuan diantaranya adalah mata pelajaran kelompok eksak dan non eksak (Sufa et al., 2017). Salah satu mata 
pelajaran tersebut adalah matematika. Matematika merupakan salah satu bidang studi atau mata pelajaran penting yang harus dipelajari oleh setiap siswa dalam berbagai jenjang pendidikan. Matematika perlu dipelajari di SD untuk membekali siswa dengan kemampuan logis dan kritis (Awalia et al., 2019). Untuk membangun pengetahaun awal siswa terhadap mata pelajaran matematika, maka matematika diajarkan sejak dini atau sekolah dasar (SD). Matematika merupakan salah satu cabang ilmu pengetahuan yang memegang peranan penting dalam pendidikan. Hal ini disebabkan karena matematika merupakan salah satu sarana berpikir ilmiah yang sangat diperlukan untuk menumbuhkembangkan daya nalar, cara berpikir logis, sistematis dan kritis. Menjadi seorang pendidik sudah harus bersemangat dalam mengembangkan ide-ide kreataif dalam menyampaikan ilmu pengetahuan sehingga menjadi bermanfaat bagi siswa. Guru dituntut untuk bisa mengajarkan dari kongkrit ke yang abstrak (Kholiyanti, 2017). Oleh sebab itu pada pembelajaran matematika erat kaitannya dengan perlunya pemahaman konsep matematika karena dengan pemahaman konsep yang matang maka siswa dapat memecahkan suatu masalah dan mampu mengaplikasikan pembelajaran pada dunia nyata. Berdasarkan hal tersebut perlu penerapan konsep kepada siswa berkaitan dengan dunia nyata sehingga siswa terlibat aktif dalam pembelajaran serta dapat mengaplikasikan konsep yang dipelajarinya dalam kehidupan sehari-hari. Banyak siswa yang mengangap bahwa matematika sebagai mata pelajaran yang paling sulit untuk dipelajari dan dipahami, tetapi semua siswa harus mempelajarinya karena matematika merupakan sarana untuk memecahkan masalah dalam kehidupan sehari-hari (Afifah \& Hartatik, 2019). Sejalan dengan itu, matematika tidak hanya tentang angka, tetapi juga sarana komunikasi (Gustina \& Rahmayuni, 2016). Untuk memperoleh pemahaman konsep yang baik, dimana siswa terlibat aktif dalam pembelajaran diperlukan ketersediaan media pembelajaran yang dapat membantu siswa dalam memahami pembelajaran salah satunya pada mata pelajaran matematika.

Sumber belajar dapat diperoleh dimana saja dan dalam bentuk apa saja yang penting dapat memfasilitasi siswa dalam belajar serta dapat mencapai tujuan pembelajaran yang diinginkan (A'yun, 2018). Media pembelajaran akan memberikan efek positif melalui pembelajaran langsung untuk keberhasilan siswa dalam belajar (Jundu et al., 2019). Sejalan dengan itu, Media dalam kegiatan proses belajar mengajar berfungsi sebagai instrumental, dengan kata lain, media berarti hanya sekedar 'alat' saja, bukan tujuan. Alat untuk membantu proses belajar, alat untuk mempermudah pemahaman masalah yang sedang dibahas, alat untuk mempermudah mengkomunikasikan hal-hal yang rumit (Eliza, 2016). Dengan demikian media pembelajaran adalah salah satu sarana yang dapat membelajarkan konsep pembelajaran agar materi yang disampaikan secara efektif dan efisien dalam rangka mencapai tujuan pembelajaran. Kendala yang terjadi selama ini adalah biaya yang tinggi dalam pembuatan media (Pratama et al., 2020). Oleh karena itu, guru harus mampu mengembangkan media yang kreatif tetapi tidak terlalu memakan banyak biaya.

Pada tanggal 4 sampai dengan 12 November 2019 peneliti melakukan observasi di kelas I SDN 52 Parupuk Tabing untuk mengetahui bagaimana pelaksanaan proses pembelajaran. Berdasarkan 
Pengembangan Media Pembelajaran Pohon Pintar Pada Materi Penjumlahan Pada Kelas I SDN 52 Parupuk Tabing (Studi Berdasarkan Asesmen), Syafni Gustina Sari, Ambiyar, Ishak Azis Citra Leffega 1209

hasil dari observasi dalam melaksanakan proses pembelajaran guru cenderung menggunakan metode ceramah, Tanya jawab, dan kemudian guru memberikan latihan atau tugas kepada siswa. Pada saat peneliti melakukan observasi di kelas IB guru sedang menjelasakan materi pada tema keluargaku, saat menjelaskan materi guru menggunakan media pembelajaran seadanya, seperti media gambar keluarga besar yang terdapat pada buku siswa dan buku guru saja seperti terlihat pada gambar 1. Guru juga belum menggembangkan dan menggunakan media pembelajaran yang menarik pada proses pembelajaran dan pada saat proses pembelajaran berlangsung siswa juga sering keluar masuk kelas, dan ada juga yang berbicara dengan teman sebangkunya, sehingga siswa sering tidak memperhatikan penjelasan materi yang disampaikan oleh guru dalam proses pembelajaran, sehingga saat membuat latihan siswa sering bertanya-tanya kepada guru kerena siswa tidak mengerti.

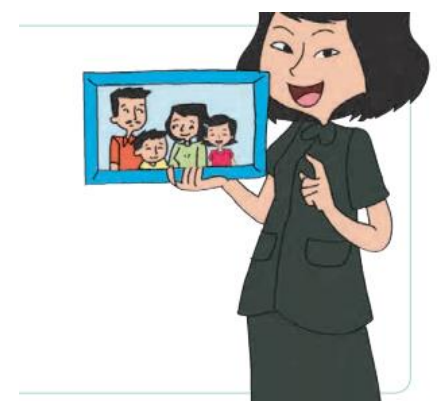

Gambar 1. Pembelajaran Tema 1 tentang keluargaku

Pada tanggal 5 November 2019 peneliti melakukan wawancara bersama guru, dari hasil wawancara ditemukan masalah siswa pada pelajaran matematika khususnya pada materi penjumlahan, yang mana masalah tersebut siswa kesulitan pada penjumlahan dua bilangan yang lebih dari satu angka, guru juga kurang mengembangkan media yang menarik yang mudah dipahami siswa pada materi penjumlahan, salah satu media pembelajaran yang digunakan guru saat menjelaskan materi penjumlahan adalah menggunakan media lidi dan media sedotan, membuat siswa kurang menarik dalam sehingga siswa kesulitan pada penjumlahan yang lebih dari satu angka. Berdasarkan hasil wawancara diperoleh fakta bahwa guru dalam proses pembelajaran perlu merancang media pembelajaran yang lebih baik dan menarik lagi dalam menjelaskan konsep materi. Sehingga dengan menggunakan media yang lebih menarik siswa mampu memahami materi yang disampaikan guru dan dapat meningkatkan minat dan belajar siswa terhadap mata pelajaran matematika khusunya pada materi penjumlahan.Dengan adanya media siswa lebih cepat mengerti materi yang disampaikan guru serta siswa dengan mudah menjawab latihan yang diberikan guru.

Dari hasil observasi ditemukan fakta bahwa Kurikulum yang digunakan disekolah adalah Kurikulum 2013.Salah satu tujuan dari kurikulum 2013 adalah memiliki kemampuan untuk kreatif. Sebagai seorang guru dituntut untuk kreatif dalam merancang proses pembelajaran khususnya pembuatan media pembelajaran.Berdasarkan dari tujuan kurikulum 2013 tersebut maka guru dapat merancang dan mengembanggkan sebuah media pembelajaran yang dapat membuat siswa lebih 
tertarik untuk belajar, khususnya belajar matematika sehingga dapat meningkatkan minat belajar siswa.

Dari masalah diatas, perlu dilakukan pengembangan media pembelajaran yang dapat membantu guru dalam menjelaskan materi serta bisa melibatkan siswa dalam pembelajaran sehingga siswa dapat memahami konsep pembelajaran dengan mudah dan menyenangkan. Kedudukan media dalam pembelajaran sangat penting bahkan sejajar dengan metode pembelajaran, karena metode yang digunakan dalam proses pembelajaran biasanya akan menuntut media apa yang dapat diintegrasikan dan diadaptasikan dengan kondisi yang dihadapi (Samura, 2015). Pengembangan Media pembelajaran dapat dilakukan oleh guru dalam rangka mewujudkan tujuan pendidikan(Batul, 2018). Salah satu media pembelajaran matematika yang dapat digunakan oleh guru kelas I SDN 52 Parupuk Tabing adalah melalui pengembangan media pembelajaran pohon pintar. Media pohon pintar dapat menstimulasi peningkatan sikap ilmiah siswa (Ulfa et al., 2019).

\section{METODE}

Penelitian ini merupukan penelitian pengembangan (research and development) dengan model pengembangan 4-D yang dimodifikasi menjadi 3-D. Menurut Thiagarajan Trianto dalam (Arywiantari et al., 2015) model 4-D terdiri dari 4 tahap pengembangan, tahap pendefenisian (define), tahap perancangan (design), tahap pengembangan (develop), dan tahap pendiseminasian (disseminate). Prosedur penelitiannya dapat dilihat pada bagan 1. Pada penelitian ini yang akan dilalui peneliti hanya sampai tahap pengembangan (develop) karena mengingat keterbatasan kemampuan waktu dan biaya.

Subjek penelitian adalah yang dapat memberikan informasi atas permasalahan yang diteliti oleh penulis.Adapun subjek yang menjadi uji coba media pembelajaran matematika pada materi penjumlahan subtema gemar berolahraga adalah peserta didikkelas I B SDN 52 Parupuk tabing, yang berjumlah 22 orang. Jenis data pada penelitian ini adalah data primer. Data primer yang dimaksud adalah data yang diperoleh secara langsung dari dosen dan guru yang diambil melalui lembar penilaian validitas dan angket pengujian praktikalitas.

Teknik pengumpulan data pada penelitian ini adalah 1) lembar validitas untuk mengumpulkan data validasi. 2) untuk penilaian praktikalitas melalui angket (kuesioner). Instrumen yang digunakan dalam mengumpulkan data penelitian ini adalah sebagai angket validitas Instrumen Penilaian media pembelajaran pohon pintar. 
Pengembangan Media Pembelajaran Pohon Pintar Pada Materi Penjumlahan Pada Kelas I SDN 52 Parupuk Tabing (Studi Berdasarkan Asesmen), Syafni Gustina Sari, Ambiyar, Ishak Azis Citra Leffega

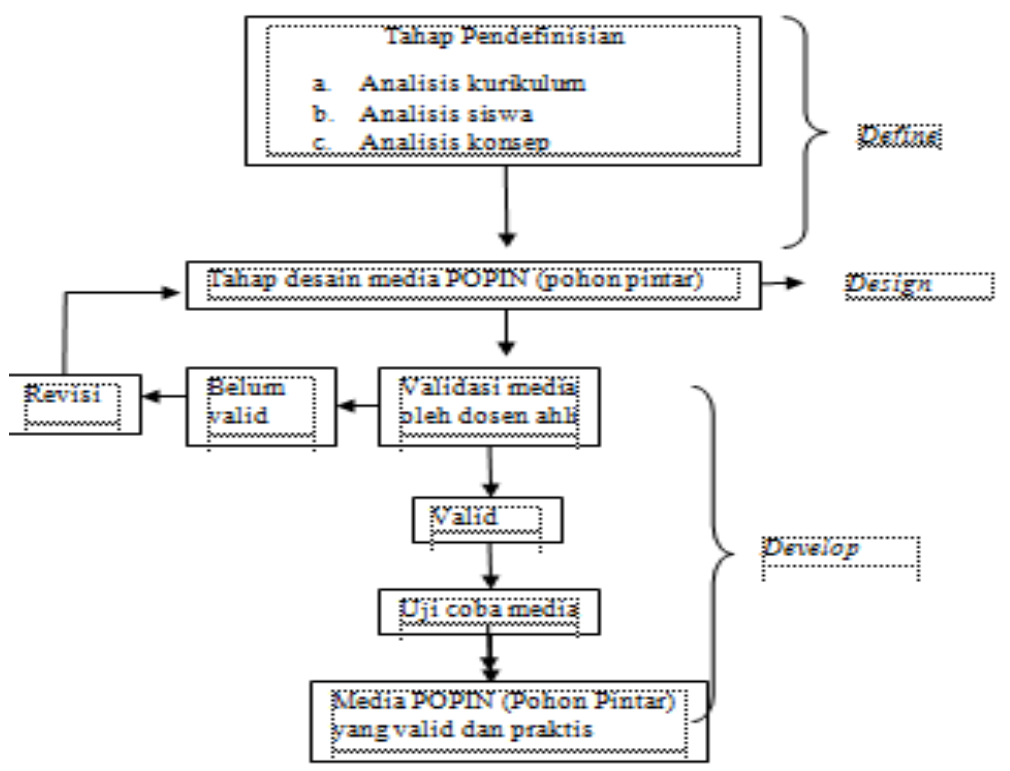

Bagan 1. Alur penelitian

\section{HASIL}

Pengembangan Media Pohon Pintar dilakukan melalui tahap pertama yaitu tahap define. Pada tahap ini Pada tahap ini dilakukan langkah-langkah seperti analisis silabus, analisis buku teks, analisis literatur, analisis karakteristik siswa dan wawancara dengan teman sejawat (Jusar, 2019). Tahap selanjutnya adalah tahap design (perancangan). Media yang telah didesain dan dikembangkan akan divalidasi oleh validator yang telah disarankan berdasarkan bidang masing-masing. Sebelum divalidasi, media yang telah dibuat mengalami beberapa kali revisi sesuai dengan saran validator,Media di validasi oleh dosen ahli.

Adapun tujuan dari validasi media dan validasi materi adalah untuk menghasilkan media pembelajaran yang valid dan layak di uji cobakan. Sebelum divalidasi media mengalami perbaikan sesuai yang disarankan oleh validator .

\section{Tabel 1.}

Rekapitulasi Hasil Analisis Validasi Media pohon pintar

\begin{tabular}{|l|l|c|l|l|}
\hline Aspek yang divalidasi & Nilai & skor Maksimal & Presentase & Kategori \\
\hline Materi & 40 & 44 & $91 \%$ & Sangat Valid \\
\hline Media & 41 & 48 & $85,5 \%$ & Valid \\
\hline Rata-rata & & $88,2 \%$ & Valid \\
\hline
\end{tabular}

Pada tabel diatas menunjukkan bahwa media pembelajaran pohon pintar pada materi penjumlahan subtema gemar berolaharaga pada kelas I SD dari ahli materi dan ahli media memenuhi kriteria valid dengan presentase $\mathbf{8 8 , 2 \%}$ yang berarti media pembelajaran dapat digunakan sebagai media pembelajaran matematika materi penjumlahan. Pohon pintar yang sudah diperbaiki sesuai saran validator ahli media dapat dilihat pada gamabar 2. 


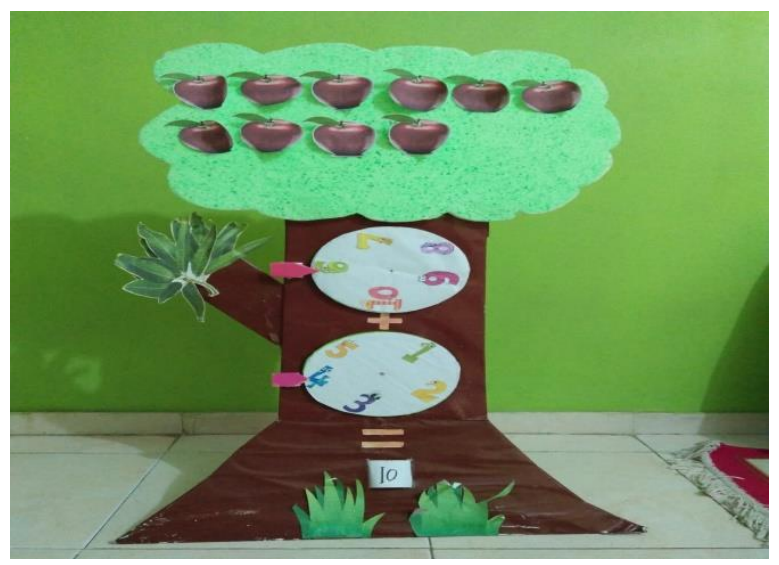

Gambar 2. Pohon Pintar

Setelah media pohon pintar pembelajaran dinyatakan valid oleh validator, kemudian dilanjutkan pada tahap praktikalitas. Praktikalitas media pohon pintar Pembelajaran oleh Guru, Angket yang diberikan kepada pendidik untuk melihat tingkat praktikalitas instrumen penilaian media pohon pintar yang terlampir pada tabel 2 dibawah ini :

Tabel 2.

Analisis Hasil Angket Praktikalitas Respon Guru

\begin{tabular}{|c|c|c|c|c|c|}
\hline \multirow{2}{*}{ No } & \multirow{2}{*}{ Aspek yang dinilai } & \multicolumn{2}{|c|}{ Penilaian Praktikalitas } & \multirow{2}{*}{$\begin{array}{l}\text { Nilai } \\
\text { Praktikalitas }\end{array}$} & \multirow{2}{*}{ Kriteria } \\
\hline & & Skor Guru & Skor Maksimal & & \\
\hline 1 & Kemudahan Pengunaan & 15 & 16 & $93,8 \%$ & Sangat Praktis \\
\hline 2 & $\begin{array}{l}\text { Efektifitas Waktu } \\
\text { Pembelajaran }\end{array}$ & 9 & 12 & $75 \%$ & Cukup Praktis \\
\hline 3. & Manfaat & 21 & 24 & $87,5 \%$ & Praktis \\
\hline & Total & 45 & 52 & $86,6 \%$ & Praktis \\
\hline
\end{tabular}

Berdasarkan data dari tabel diatas dapat dijelaskan persentase praktikalitas Media Pembelajaran Pohon Pintar Pada Materi Penjumlahan Subtema Gemar Berolahraga Pada Kelas Ioleh guru adalah 86,6\% dengan kriteria praktis. Hal ini menunjukkan bahwa Media Pembelajaran Pohon Pintar praktis digunakan oleh guru sebagai sumber atau media belajar pada materi Penjumlahan.

Angket respon siswa diisi oleh seluruh siswa kelas I.B yang berjumlah 21. Angket respon siswa diisi setelah proses pembelajaran yang disampaikan setelah berakhir dengan menggunakan media pembelajaran Pohon Pintar Kelas I SD pada tanggal 4 Maret 2020 pukul 10.00 WIB. Adapun hasil analisis angket praktikalitas respon siswa dapat dilihat pada tabel 3.

Tabel 3.

Hasil Praktikalitas Media Pembelajaran Pohon pintar oleh Siswa

\begin{tabular}{|c|c|c|c|c|c|}
\hline \multirow{2}{*}{ No } & \multirow{2}{*}{ Aspek yang dinilai } & \multicolumn{2}{|c|}{ Penilaian Praktikalitas } & \multirow{2}{*}{$\begin{array}{c}\text { Nilai } \\
\text { Praktikalitas }\end{array}$} & \multirow{2}{*}{ Kriteria } \\
\cline { 3 - 4 } & $\begin{array}{c}\text { Skor Peserta } \\
\text { Didik }\end{array}$ & $\begin{array}{c}\text { Skor } \\
\text { Maksimal }\end{array}$ & \\
\hline 1 & Pembelajaran & 403 & 420 & $95,9 \%$ & Sangat Praktis \\
\hline 2 & Media & 318 & 336 & $94,6 \%$ & Sangat Praktis \\
\hline \multicolumn{2}{|c|}{ Total } & 721 & 756 & $95,4 \%$ & Sangat Praktis \\
\hline
\end{tabular}


Pengembangan Media Pembelajaran Pohon Pintar Pada Materi Penjumlahan Pada Kelas I SDN 52 Parupuk Tabing (Studi Berdasarkan Asesmen), Syafni Gustina Sari, Ambiyar, Ishak Azis Citra Leffega 1213

Berdasarkan Tabel 3. Dapat dilihat hasil praktikalitas Media Pembelajaran Pohon Pintar oleh siswa yaitu $95,4 \%$ yang artinya Media dengan kriteria sangat praktis.

Validasi materi didasarkan pada dua aspek penilaian yaitu materi dan penyajian, pada validasi materi ini validatornya satu orang diperoleh rata-rata validitas sebesar $91 \%$ dengan kriteria sangat valid. Berdasarkan aspek penilaian materi diperoleh nilai validitas 90,6\% dengan kriteria sangat valid. Hal tersebut menunjukkan bahwa media sudah memenuhi materi yang sesuai dengan kompetensi dan indikator. Aspek penilaian penyajian diperoleh nilai validitas 91,6\% dengan ktiteria sangat valid. Hal ini menunjukkan bahwa media sudah memenuhi penyajian yang menarik. Hasil validasi ahli materi dapat disimpulkan bahwa media memperoleh rata-rata 91\% dengan ktiteria sangat valid. Validasi instrumen dimaksudkan untuk memastikan bahwa instrumen yang telah dibuat layak digunakan dan memang mengukur apa yang hendak diukur (Ernawati, 2017).

Validasi media didasarkan pada dua aspek yang dinilai yaitu tampilan dan penggunaan yang memperoleh rata-rata validitas sebesar $85,5 \%$ dengan kriteria valid. Berdasarkan aspek penilaian tampilan diperoleh nilai validitas $84,3 \%$ dengan kriteria valid. Hal tersebut menunjukkan bahwa media sudah memenuhi penyajian media dengan bahan yang tidak berbahaya dan mudah didapatkan serta komponen yang dibuat dalam media seperti angka, simbol dan pemilihan warna sudah baik dan menarik. Aspek penilaian penggunaan diperoleh nilai validitas $87,5 \%$ dengan ktiteria valid. Hal ini menunjukkan bahwa media sudah memenuhi penggunaan media dengan mudah digunakan, praktis, serta ukurun media sesuai dengan kebutuhan siswa. Hasil validasi ahli media dapat disimpulkan bahwa media memperoleh rata-rata85,5\% dengan ktiteria valid. Berdasarkan hasil validitas media diatas, media pembelajaran yang dikembangkan telah dapat dijadikan sebagai dalam proses pembelajaran.

Guru berperan dalam hal perolehan data tentang kepraktisan perangkat pembelajaran keseluruhan (Dwijayani, 2017). Hasil dari analisis data hasil uji praktikalitas oleh guru kelas I SDN 52 Parupuk Tabing menunjukkan bahwa media pembelajaran pohon pintar yang telah dikembangkan memperoleh hasil 86,6\% dengan kriteria praktis. Angka tersebut didapatkan dari rata-rata tiga aspek yaitu aspek kemudahan media, aspek efektifitas waktu pembejaran dan aspek manfaat .

Dari aspek kemudahan media pembelajaran pohon pintar yang telah dikembangkan dinyatakan sangat praktis dengan persentase kepraktisan 93,8\%. Hal ini menunjukkan bahwa media yang telah dikembangkan dapat digunakan sebagai alternatif media atau bahan ajar serta memudahkan guru dalam memotivasi peserta didik untuk belajar dan dapat membantu guru dalam proses pembelajaran.

Dari aspek efektifitas waktu pembelajaranmedia pembelajaran pohon pintaryang telah dikembangkan dinyatakan cukup praktis dengan persentase kepraktisan $75 \%$. Hal ini menunjukkan bahwa media pembelajaran pohon pintar yang telah dikembangkan memudahkan guru dalam waktu melaksanakan pembelajaran. 
Dari aspek manfaat media pembelajaran pohon pintar yang telah dikembangkan dinyatakan praktis dengan presentase kepraktisan $87,5 \%$. Menunjukan bahwa media yang telah dikembangkan dapat membantu guru dalam proses belajar mengajar.Pengisian angket praktikalitas media pohon pintar oleh guru dilakukan setelah pembelajaran selesai dilaksanakan.

Analisis data hasil uji praktikalitas oleh siswa kelas I SDN 52Parupuk tabing menunjukkan bahwa media pembelajaran pohon pintar materi penjumlahanyang telah dikembangkan memperoleh hasil 95,4\% dengan kriteria sangat praktis.Angka tersebut didapatkan dari rata-rata dua aspek yaitu aspek kepraktisan pembelajaranmedia dan aspek media pohon pintar.Dari aspek kepraktisan pembelajaran media pembelajaran pohon pintar yang telah dikembangkan dinyatakan sangatpraktis dengan persentase kepraktisan 95,9\%. Hal ini menunjukkan bahwa media yang telah dikembangkan dapat membuat peserta didik tertarik untuk menggunakannya dalam proses pembelajaran. Dari aspek manfaat media pembelajaran pohon pintar yang telah dikembangkan dinyatakan sangat praktis dengan persentase kepraktisan 94,6\%. Hal ini menunjukkan bahwa media yang telah dikembangkan memudahkan peserta didik memahami materi, memudahkan peserta didik menemukan konsep. Secara umum, manfaat media dalam proses pembelajaran adalah memperlancar interaksi antara guru dengan siswa sehingga pembelajaran akan lebih efektif dan efisien (Karo-Karo, 2017).

\section{KESIMPULAN}

Berdasarkan data uji coba media pembelajaran pohon pintar pada mata pelajaran Matematika, materi penjumlahan subtema 2 (gemar berolahraga), diperoleh kesimpulan sebagai berikut 1) Validitas Media Pembelajaran Pohon Pintar Materi Penjumlahan untuk Kelas I SD yang telah dikembangkan kategori valid dengan rata-rata persentase kevalidan 88,2\%, berarti bahwa media pembelajaran pohon pintar materi penjumlahan untuk kelas I SD yang dikembangkan sudah memenuhi Kriteria sehingga dapat digunakan tanpa revisi sebagai media pembelajaran Matematika kelas I Sekolah Dasar. 2) Praktikalitas Media Pembelajaran Pohon Pintar Materi Penjumlahan Untuk Kelas I SD yang telah dikembangkan kategori praktis oleh guru dengan persentase kepraktisan 86,6\% dan sangat praktis oleh siswa dengan persentase kepraktisan 95,5\%.Hal tersebut menunjukan bahwa guru dan siswa dapat menggunakan mediadalam pembelajaran dengan baik

\section{DAFTAR PUSTAKA}

A'yun, N. Q. (2018). PENGEMBANGAN MEDIA INTERAKTIF SI PONTAR BERBASIS APLIKASI ANDROID MATERI KPK DAN FPB MATA PELAJARAN MATEMATIKA KELAS IV SD. JPGSD. Volume 06 Nomor 02 Tahun 2018, 47-56 Bangsa, 6(2), 47-56.

Afifah, N., \& Hartatik, S. (2019). Pengaruh Media Permainan Ular Tangga terhadap Motivasi Belajar pada Pelajaran Matematika Kelas II SD Kemala Bhayangkari 1 Surabaya. MUST: Journal of Mathematics Education, Science and Technology, 4(2), 209. https://doi.org/10.30651/must.v4i2.3035 
Pengembangan Media Pembelajaran Pohon Pintar Pada Materi Penjumlahan Pada Kelas I SDN 52 Parupuk Tabing (Studi Berdasarkan Asesmen), Syafni Gustina Sari, Ambiyar, Ishak Azis Citra Leffega 1215

Arywiantari, D., Agung, A. . G., \& Tastra, I. D. K. (2015). Pengembangan multimedia interaktif pada pembelajaran IPA di SMP Negeri 2 singaraja. Jurnal Edutech Universitas Pendidikan Ganesha, 3(1), 3-12.

Awalia, I., Pamungkas, A. S., \& Alamsyah, T. P. (2019). Pengembangan Media Pembelajaran Animasi Powtoon pada Mata Pelajaran Matematika di Kelas IV SD. Kreano, Jurnal Matematika Kreatif-Inovatif, 10(1), 49-56. https://doi.org/10.15294/kreano.v10i1.18534

Batul, R. Z. (2018). Pengembangan Media Pembelajaran Pohon Pintar Pada Kompetensi Dasar Menerapkan Promosi Produk Kelas X Bisnis Daring Dan Pemasaran Smk Negeri 2 Blitar. $\begin{array}{lllll}\text { Jurnal Pendidikan } & \text { Tata Niaga }\end{array}$ https://ejournal.unesa.ac.id/index.php/jptn/article/view/25736

Dwijayani, N. M. (2017). Pengembangan Media Pembelajaran Moodle. Jurnal Ma t Ema Tika K r Ea Tif -Ino v a Tif, 7(2), 126-132. https://doi.org/10.26877/jp2f.v7i2.1311

Eliza, R. (2016). Media Pembelajaran Sebagai Sarana Komunikasi Matematika Di Sekolah Dasar. Ta'dib, 13(2). https://doi.org/10.31958/jt.v13i2.186

Ernawati, I. (2017). Uji Kelayakan Media Pembelajaran Interaktif Pada Mata Pelajaran Administrasi Server. Elinvo (Electronics, Informatics, and Vocational Education), 2(2), 204-210. https://doi.org/10.21831/elinvo.v2i2.17315

Gustina, S., \& Rahmayuni, I. (2016). Pengembangan Potensi Estetik Dalam Pembelajaran Matematika Sekolah Dasar. Jurnal Pelangi, 8(2), 191-202.

Jundu, R., Jehadus, E., Nendi, F., Kurniawan, Y., \& Men, F. E. (2019). Optimalisasi Media Pembelajaran Interaktif dalam Meningkatkan Kemampuan Matematis Anak di Desa Popo Kabupaten Manggarai. E-Dimas: Jurnal Pengabdian Kepada Masyarakat, 10(2), 221. https://doi.org/10.26877/e-dimas.v10i2.3353

Jusar, I. R. (2019). PRATIKALITAS MODUL PECAHAN BERBASIS NILAI-NILAI KEISLAMAN. Jurnal MEDIA BINA ILMIAH, 44(12), 2-8. https://doi.org/10. 19540 /j. cnki. cjcmm. 20190128. 002

Karo-Karo, I. R. (2017). MANFAAT MEDIA DALAM PEMBELAJARAN. Jurnal AXIOM, 2(1), 91-96.

https://ejournal.poltektegal.ac.id/index.php/siklus/article/view/298\%0Ahttp://repositorio.unan.ed u.ni/2986/1/5624.pdf\%0Ahttp://dx.doi.org/10.1016/j.jana.2015.10.005\%0Ahttp://www.biomedc entral.com/1471-2458/12/58\%0Ahttp://ovidsp.ovid.com/ovidweb.cgi?T=JS\&P

Kholiyanti, A. (2017). PEMBELAJARAN MATEMATIKA DARI KONKRIT KE ABSTRAK DALAM MEMBANGUN KONSEP DASAR GEOMETRI BAGI SISWA SEKOLAH DASAR. Journal of Chemical Information and Modeling, 53(9), 1689-1699.

Pratama, L. D., Lestari, W., \& Astutik, I. (2020). Efektifitas Penggunaan Media Edutainment Di Tengah Pandemi Covid-19. AKSIOMA: Jurnal Program Studi Pendidikan Matematika, 9(2), 413-423. https://doi.org/10.24127/ajpm.v9i2.2783 
Samura, A. O. (2015). Penggunaan media dalam pembelajaran matematika dan manfaatnya. Delta-Pi: Jurnal Matematika Dan Pendidikan Matematika, 4(1), 69-79.

Sufa, L. N., Cahyadi, F., Fita, M., \& Untari, A. (2017). Penerapan Media Diorama Skala terhadap Kemampuan Berpikir Tingkat Tinggi Siswa Kelas V SD Negeri 1 Ujungpandan INFORMASI ARTIKEL. 2(2), 52-62. https://media.neliti.com/media/publications/222475-penerapan-mediadiorama-skala-terhadap-k.pdf

Ulfa, C. R., Ellianawati, E., \& Darsono, T. (2019). Media Pohon Pintar dalam Pembelajaran Kooperatif untuk Menstimulasi Sikap Ilmiah Siswa. UPEJ Unnes Physics Education Journal, 8(2), 170-177. https://doi.org/10.15294/upej.v8i2.33325 